\title{
Sciendo
}

LATVIAN JOURNAL OF PHYSICS

AND TECHNICAL SCIENCES

2019, N 1

DOI: $10.2478 /$ lpts-2019-0004

\section{INVESTIGATION OF WIRELESS CHANNELS OF 802.11 STANDARD \\ IN THE 5GHZ FREQUENCY BAND}

\author{
Dmytro V. Mykhalevskiy \\ Department of Telecommunication Systems and Television \\ Vinnytsia National Technical University, 21021, 95 Khmelnytske Highway, \\ Vinnytsia, UKRAINE \\ adotq@ukr.net
}

The paper presents the study of wireless channel over-the-air channels of the family of $802.11 \mathrm{x}$ standards within the $5 \mathrm{GHz}$ frequency band, taking into account the influence of architectural obstacles within premises. The following parameters have been selected as the main parameters in the course of the study: an efficient rate of information transmission, signal power at the receiver input, as well as channel carrying capacity. As a result of the experimental study, the author has found out relevant mathematical expression for estimation of the efficiency criterion of wireless channels of the family of $802.11 \mathrm{x}$ standards for the $5 \mathrm{GHz}$ frequency band, taking into account relevant architectural obstacles within premises.

Keywords: architectural obstacles, effective data rate, efficiency factor, signal strength, threshold value

\section{INTRODUCTION}

Presence of quite essential quantity of devices, which require connection to the network, envisages utilisation of wireless technologies of the family of $802.11 \mathrm{x}$ standards because they are one of the optimum solutions for creation of the general network [1], [2].

Networks of the family of $802.11 x$ standards are characterised by the steady development in the direction of increase of the main criterion of efficiency (efficient rate of information transmission). Taking into account the quite wide utilisation of the wireless networks, it is possible to state that a number of negative factors may appear, which can essentially worsen transfer characteristics of wireless channels of information transmission. Therefore, search of new methods and facilities for minimisation of influence of these factors is the vital task at present because such minimisation is aimed, in the first turn, at improvement of characteristics of the main quality criterion (efficient rate of information transmission).

After analysing the scientific works [3]-[11], we can conclude that it is 
possible to state that wireless channels of the family of $802.11 \mathrm{x}$ standards are under quite strong dependence on the external destabilising factors. In this situation, quite essential fluctuations of the main criteria of efficiency occur. Therefore, the present paper will try to estimate the influence of one of the main destabilising factors (i.e., architectural obstacles) upon the main criteria of efficiency of wireless channels of the family of $802.11 \mathrm{x}$ standards for the $5 \mathrm{GHz}$ frequency band.

\section{MATERIALS AND METHODS}

The network was created on the basis of the access point (AP) supporting all existing standards 802.11 for the $5 \mathrm{GHz}$ frequency band. In addition, this AP supports the MIMO technology with three transmitting and receiving antennas (it is the most widely used equipment, which is presented on the market). For this study, the author has selected a standard premise, within which length of the wireless channel could be equal up to $15 \mathrm{~m}$. To estimate the influence of architectural obstacles, the author has envisaged the introduced error IE1 at the distance of $l_{1}=3 \mathrm{~m}$, as well as the introduced error IE2 at the distance of $l_{1}+l_{2}=6 \mathrm{~m}$.

For this study, the following main parameter has been selected: the efficient rate of information transmission $V$, which is the main parameter of the criterion of the channel efficiency and which is determined by additions of the upper level of the network. In this situation, it is possible to determine the criterion of the channel efficiency as follows:

$$
K=\frac{V}{V_{p l}},
$$

where $V$ is the efficient rate of information transmission; $V_{p l}$ is maximum carrying capacity of the channel, which is determined by the rate of conversion of frames into a bit sequence at the physical level and which is standardised in the specifications of the standard 802.11.

As this parameter (i.e., the rate of information transmission) is in direct dependence on characteristics of transmission of signals, the other parameter has been selected: the signal power at the receiver input $P$ (RSSI). Estimation of the signal power has been performed through averaging the results of measurements during five minutes on the condition that the period of obtaining relevant values is equal to one second [5].

\section{RESULTS AND DISCUSSION}

\section{Analysis of Results of Experimental Study}

The proposed methodology was used as the basis for performance of the experimental study of the main determined parameters of wireless channels of the family of $802.11 \mathrm{x}$ standards in the $5 \mathrm{GHz}$ frequency band in order to estimate 
dependence of their characteristics on certain factors of the transmission medium, such as architectural obstacles. Overall, six wireless channels were investigated. Maximum values of the parameter of carrying capacity at the physical level $\left(\mathrm{V}_{\mathrm{pl}}\right.$ ${ }_{\max } \mathrm{MB} / \mathrm{s}$ ) of these channels are as follows: $802.11 \mathrm{a}-54 ; 802.11 \mathrm{n}, 20 \mathrm{MHz}-216.7$; $802.11 \mathrm{n}, 40 \mathrm{MHz} ; 802.11 \mathrm{ac}, 20 \mathrm{MHz}-288.9 ; 802.11 \mathrm{ac}, 40 \mathrm{MHz}-600 ; 802.11 \mathrm{ac}$, $80 \mathrm{MHz}-1300$. Variable parameter $L$ is the length of the wireless channel.

The study was carried out for the following standard situations, which usually occur within the premises: open space; presence of a single door; presence of two doors; presence of one or two walls. Experimental characteristics of the channel parameters were used: a - dependence of the efficient rate of transmission on the distance between the receiver and transmitter; $b$ - dependence of the efficient rate of transmission on the signal power at the receiver input; $\mathrm{c}-$ dependence of the rate of transmission at the physical level on the distance between the receiver and transmitter; $\mathrm{d}$ - dependence of the rate of transmission at the physical level on the signal power at the receiver input.

Open space. Open space is the most widely used scheme of construction of wireless channels of the family of $802.11 x$ standards, when networks are created within premises. Characteristics of the channel parameters for the open space model are shown in Fig. 1.

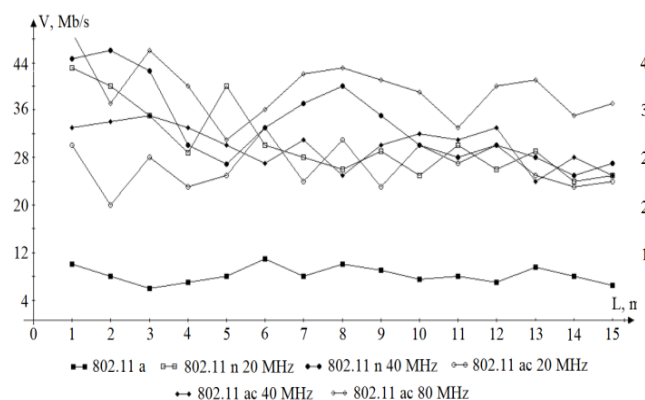

a

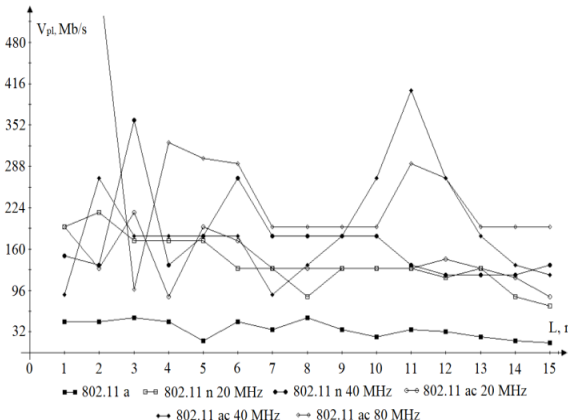

c

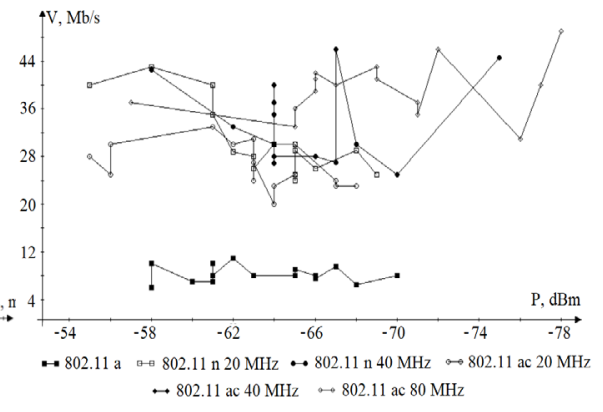

b

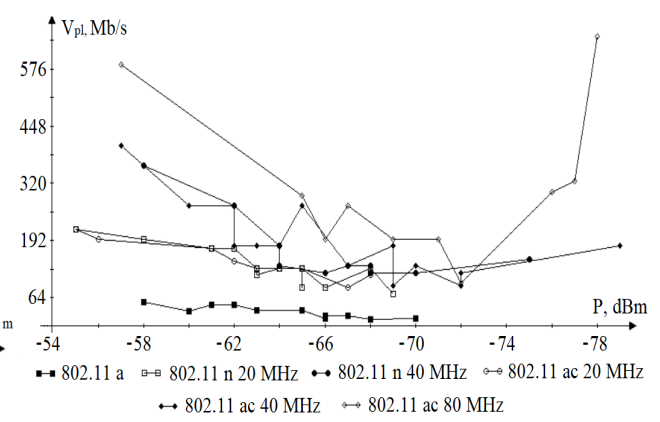

d

Fig. 1. Experimental characteristics of the channel parameters for the open space model.

Study results demonstrate the presence of fluctuations of the efficient rate of information transmission, which are in direct dependence of fluctuations of the signal distribution within the premises. At the same time, it is possible to estimate fluctuations of the signal for the $5 \mathrm{GHz}$ frequency band in accordance with the method, 
which was proposed by paper [4] for $2.4 \mathrm{GHz}$ band. In this situation, confidence interval will vary. It is possible to write down the interval of change of fluctuations of the signal power for a general situation in the following manner:

$$
P_{\tilde{n}}-\delta<P(\Delta \mathrm{c} \Delta \mathrm{g} \Delta \mathrm{a} \Delta \mathrm{b}) \leq P_{\tilde{n}}+\delta
$$

where $\Delta c, \Delta g, \Delta a, \Delta b$ are the coefficients, which determine the limits of permissible variations of the signal attenuation coefficients; $P_{c}$ is the average value of the signal power at the receiver input; $\delta$ is the coefficient of the signal fluctuations at the receiver input, which may be considered as the confidence interval.

Each confidence interval will be in correspondence with the interval of fluctuations for the selected parameter (i.e., for the rate of information transmission). Then, in respect of each standard under investigation, it would be possible to determine the relevant confidence interval for the efficient rate of information transmission $\Delta V$, which will be in correspondence with the confidence interval of the signal fluctuations $\delta$. Therefore, in respect of the open space channels, it is possible to write the following:

$$
\begin{aligned}
& \delta_{a} \approx \pm 5 \mathrm{dBm} ; \Delta V_{a} \approx \pm 2 \mathrm{Mb} / \mathrm{s} ; \\
& \delta_{n 20} \approx \pm 5 \mathrm{dBm} ; \Delta V_{n 20} \approx \pm 4 \mathrm{Mb} / \mathrm{s} ; \\
& \delta_{n 40} \approx \pm 5 \mathrm{dBm} ; \Delta V_{n 40} \approx \pm 8 \mathrm{Mb} / \mathrm{s} ; \\
& \delta_{a c 20} \approx \pm 5 \mathrm{dBm} ; \Delta V_{a c 20} \approx \pm 4 \mathrm{Mb} / \mathrm{s} ; \\
& \delta_{a c 40} \approx \pm 7 \mathrm{dBm} ; \Delta V_{a c 40} \approx \pm 8 \mathrm{Mb} / \mathrm{s} ; \\
& \delta_{a c 80} \approx \pm 10 \mathrm{dBm} ; \Delta V_{a c 80} \approx \pm 8 \mathrm{Mb} / \mathrm{s} .
\end{aligned}
$$

As it may be seen from the results obtained for the confidence intervals, an increase in the carrying capacity of a channel at the expense of the spread spectrum of this channel results in the increase of the level of fluctuations. This statement is correct both for the selected parameter and for the efficient rate of information transmission in respect of any standard. In addition, this statement is evidenced by the characteristics of the selected parameter $V_{p l}$, which are shown in Fig. 2c, where one may observe quite an essential dynamics of change in the values, which are determined by the MCS scheme [2].

A single obstacle - wood. This diagram simulates presence of architectural obstacles in a channel, such as wooden doors. As shown in paper [12] for $2.4 \mathrm{GHz}$ band, in the case of presence of a single door there is an effect of increase in the efficient rate of information transmission directly following these doors. Relevant characteristics are shown in Fig. 2. The characteristics obtained demonstrate that the signal power at the receiver input is characterised by the fluctuations, which are similar to the fluctuations that were observed in the previous situation (however, there is an exclusion). 


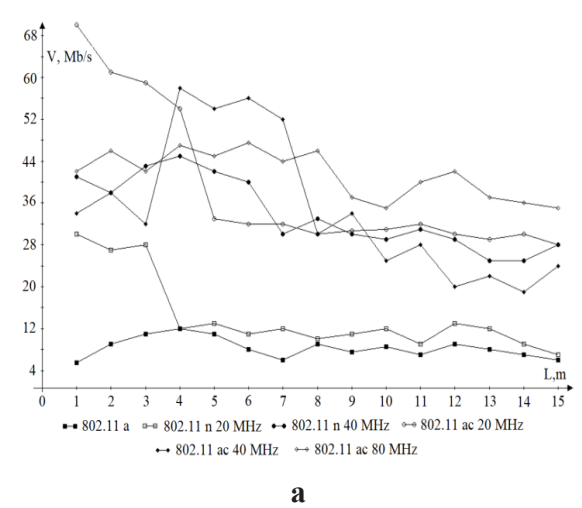

a

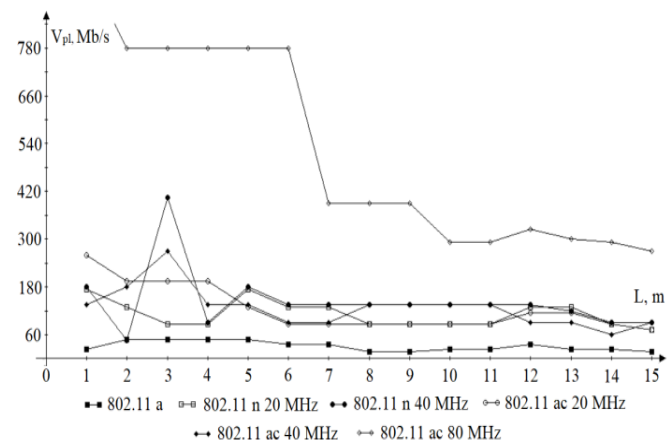

c

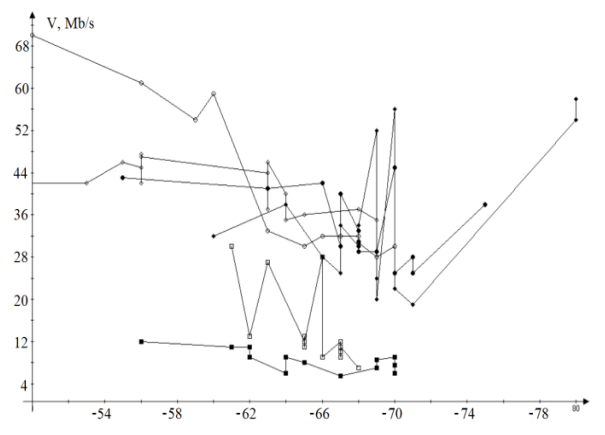

$\because 802.11$ a $\rightarrow 802.11 \mathrm{n} 20 \mathrm{MHz} \longrightarrow 802.11 \mathrm{n} 40 \mathrm{MHz} \leadsto 802.11 \mathrm{ac} 20 \mathrm{MHz} \quad \mathrm{P}, \mathrm{dBm}$ $\rightarrow 802.11$ ac $40 \mathrm{MHz} \leftrightarrow 802.11$ ac $80 \mathrm{MHz}$

b

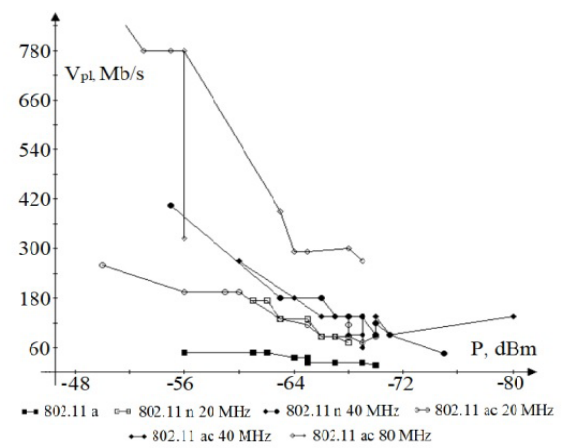

d

Fig. 2. Experimental characteristics of the channel parameters in the case of presence of a single obstacle.

The interval of fluctuations of the confidence interval is as follows:

$$
\begin{aligned}
& \delta_{a} \approx \pm 7 \mathrm{dBm} ; \Delta V_{a} \approx \pm 3 \mathrm{Mb} / \mathrm{s} ; \\
& \delta_{n 20} \approx \pm 6 \mathrm{dBm} ; \Delta V_{n 20} \approx \pm 4 \mathrm{Mb} / \mathrm{s} ; \\
& \delta_{n 40} \approx \pm 10 \mathrm{dBm} ; \Delta V_{n 40} \approx \pm 6 \mathrm{Mb} / \mathrm{s} ; \\
& \delta_{a c 20} \approx \pm 9 \mathrm{dBm} ; \Delta V_{a c 20} \approx \pm 4 \mathrm{Mb} / \mathrm{s} ; \\
& \delta_{a c 40} \approx \pm 15 \mathrm{dBm} ; \Delta V_{a c 40} \approx \pm 10 \mathrm{Mb} / \mathrm{s} ; \\
& \delta_{a c 80} \approx \pm 15 \mathrm{dBm} ; \Delta V_{a c 80} \approx \pm 10 \mathrm{Mb} / \mathrm{s} .
\end{aligned}
$$

As it may be seen from this analysis, exclusions are related to the medium of transmission near the architectural obstacle. There are quite high fluctuations of characteristics. It is possible to state that presence of a single obstacle has a minimum influence and one may neglect this influence. A single inessential increase in fluctuations is observed for the standard 802.11ac for the wideband channels, and this increase can be explained by an increase in the channel instability.

Two obstacles - wood. Such a situation is quite standard for dwelling houses and office premises. Study results are shown in Fig. 3. 


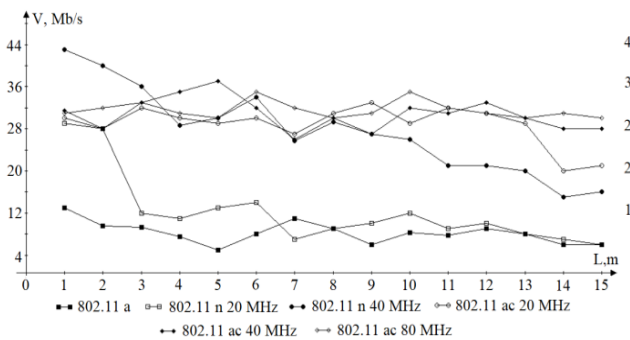

$\rightarrow 802.11$ ac $40 \mathrm{MHz} \leftrightarrow 802.11$ ac $80 \mathrm{MHz}$

a

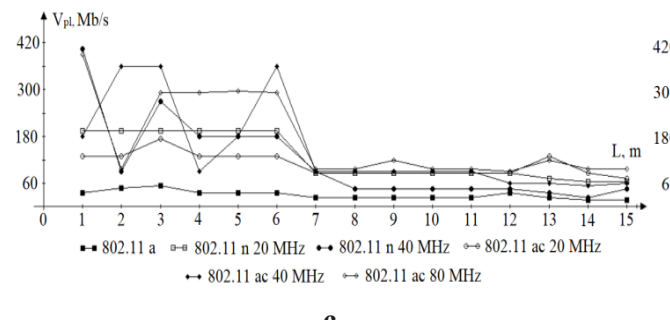

c

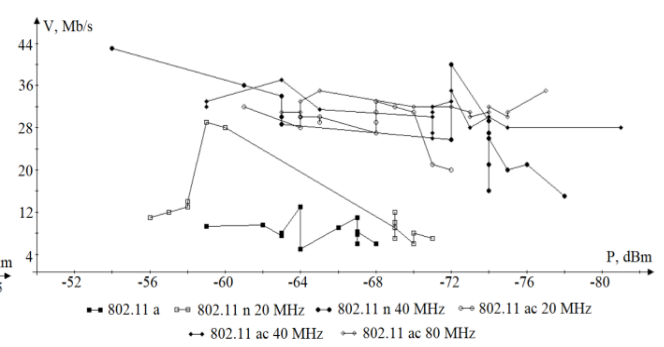

b

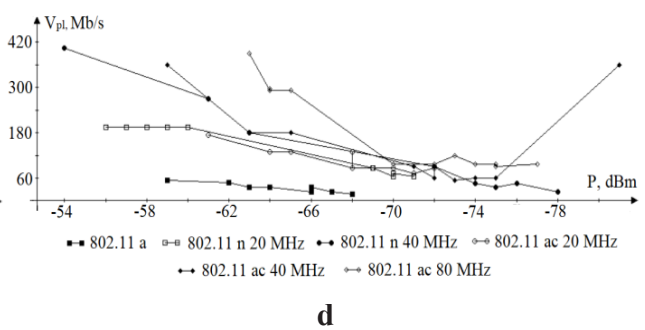

d

Fig. 3. Experimental characteristics of the channel parameters in the case of presence of two obstacles.

It is possible to write the fluctuations parameters of the main efficiency parameters of channels in the following manner:

$$
\begin{aligned}
& \delta_{a} \approx \pm 5 \mathrm{dBm} ; \Delta V_{a} \approx \pm 4 \mathrm{Mb} / \mathrm{s} ; \\
& \delta_{n 20} \approx \pm 6 \mathrm{dBm} ; \Delta V_{n 20} \approx \pm 6 \mathrm{Mb} / \mathrm{s} ; \\
& \delta_{n 40} \approx \pm 7 \mathrm{dBm} ; \Delta V_{n 40} \approx \pm 7 \mathrm{Mb} / \mathrm{s} ; \\
& \delta_{a c 20} \approx \pm 6 \mathrm{dBm} ; \Delta V_{a c 20} \approx \pm 6 \mathrm{Mb} / \mathrm{s} ; \\
& \delta_{a c 40} \approx \pm 8 \mathrm{dBm} ; \Delta V_{a c 40} \approx \pm 7 \mathrm{Mb} / \mathrm{s} ; \\
& \delta_{a c 80} \approx \pm 10 \mathrm{dBm} ; \Delta V_{a c 80} \approx \pm 7 \mathrm{Mb} / \mathrm{s} .
\end{aligned}
$$

Presence of the second obstacle made of wood in the wireless channel causes a decrease in the value of the signal power at the receiver input by $5 \mathrm{dBm}$ on the average. The efficient rate of information transmission is characterised by the greatest attenuation coefficient following the second obstacle. In addition, presence of the second obstacle in the wireless channel of the standard 802.11 decreases the level of fluctuations as compared with the previous situation. It follows from the charts, which are shown in Fig. 4c, that there is a certain threshold value of level of the signal power at the receiver input, below which the wireless channel begins to work in the operation mode, which is equivalent to $802.11 \mathrm{n}$ operation mode in the $20 \mathrm{MHz}$ frequency band.

Obstacles - walls. As a rule, presence of walls (as obstacles) in the wireless channel causes quite high attenuation of the signal. Study results are shown in Fig. 4. 


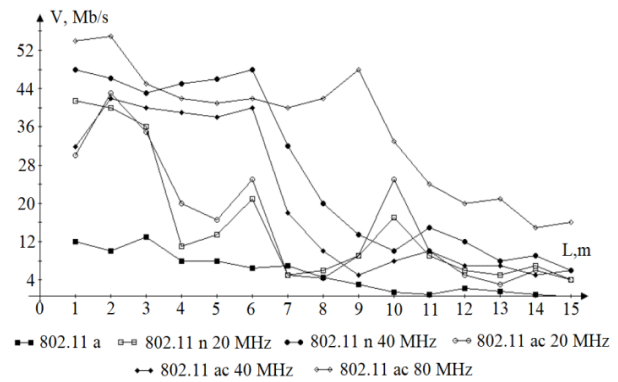

a

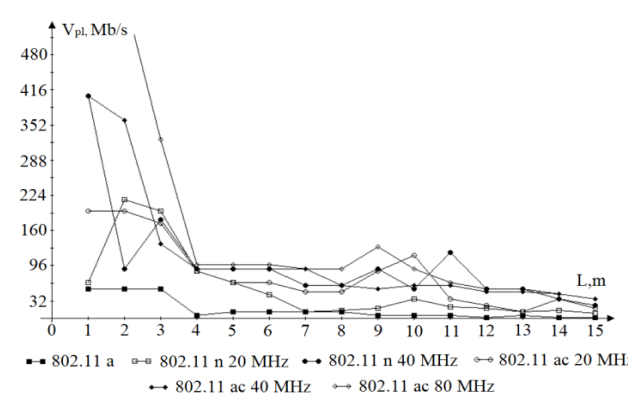

C

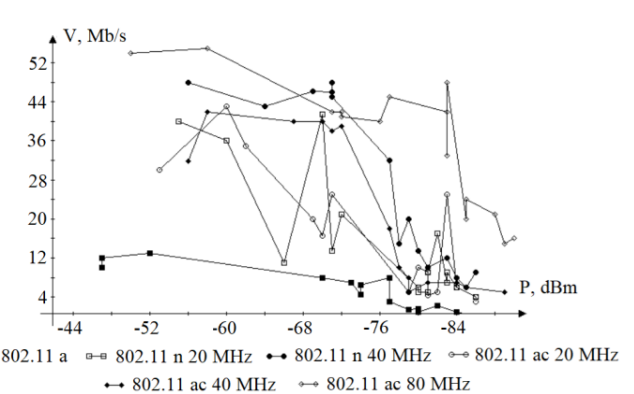

b

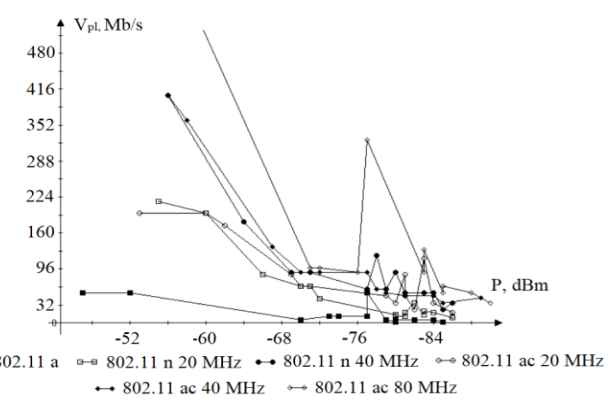

d

Fig. 4. Experimental characteristics of the channel parameters in the case of presence of two walls.

In this case, it is possible to observe the same restriction of carrying capacity of a channel at the physical level, and this fact confirms the assumption concerning the threshold value of the parameter of the signal power. One of the methods, which are aimed at improvement of characteristics of the efficient rate of transmission following the obstacle, is related to the use of wideband channels. Presence of the second obstacle in the channel causes an increase in the slope of attenuation of characteristics. The confidence interval for this situation is as follows:

$$
\begin{aligned}
& \delta_{a} \approx \pm 15 \mathrm{dBm} ; \Delta V_{a} \approx \pm 3 \mathrm{Mb} / \mathrm{s} ; \\
& \delta_{n 20} \approx \pm 15 \mathrm{dBm} ; \Delta V_{n 20} \approx \pm 4 \mathrm{Mb} / \mathrm{s} ; \\
& \delta_{n 40} \approx \pm 17 \mathrm{dBm} ; \Delta V_{n 40} \approx \pm 6 \mathrm{Mb} / \mathrm{s} ; \\
& \delta_{a c 20} \approx \pm 16 \mathrm{dBm} ; \Delta V_{a c 20} \approx \pm 4 \mathrm{Mb} / \mathrm{s} ; \\
& \delta_{a c 40} \approx \pm 17 \mathrm{dBm} ; \Delta V_{a c 40} \approx \pm 10 \mathrm{Mb} / \mathrm{s} ; \\
& \delta_{a c 80} \approx \pm 20 \mathrm{dBm} ; \Delta V_{a c 80} \approx \pm 10 \mathrm{Mb} / \mathrm{s} .
\end{aligned}
$$

Therefore, presence of various architectural obstacles results in the same nature of influence, which depends on the thickness and density of the material, which is used for this purpose. This statement is correct on the condition that the level of the signal power does not fall below a certain threshold value. Therefore, in this case it is possible to state that architectural obstacles have a character of the additive coefficient of influence upon the efficiency parameters of the wireless channels of the family of $802.11 x$ standards for the $5 \mathrm{GHz}$ frequency band. 
On the basis of formula 1 , as well as in accordance with the obtained results of experimental study, it is possible to determine the efficiency coefficient of the wireless channel for each situation under investigation with the help of the method of mathematical regression. In this case, it is possible to write the general mathematical model for estimation of the efficiency parameters as follows:

$$
\begin{aligned}
& V(l) \approx-u \cdot l+s, \\
& V_{p l}(l) \approx-h l+x,
\end{aligned}
$$

where $u, h$ are attenuation coefficients of characteristics (dimensionality of which is $\mathrm{Mb} / \mathrm{m})$; $\mathrm{s}$ and $\mathrm{x}$ are initial coefficients of the efficient rate of transmission and carrying capacity of a channel, respectively; $l$ - length of the wireless channel or length of the radio circuit.

Taking into account the conception of construction of the multiservice networks, as well as the mechanism, which ensures quality of provision of the information-and-communication services [13], the parameter of the efficient rate of information transmission must be determined by the minimum value of fluctuations within the confidence interval. Then, it is possible to write the efficiency coefficient of the wireless channel in the following manner:

$$
K \approx \frac{s-u \cdot l-\Delta V}{V_{p l \text { max }}},
$$

Coefficient of change of the carrying capacity of a channel is determined as follows:

$$
K_{p l} \approx \frac{x-h l}{V_{p l \text { max }}},
$$

With the help of method of averaging the estimation of fluctuations of the obtained characteristics, it is possible to determine attenuation coefficients of the regression results. These results are presented in Table 1. 
Values of Attenuation Coefficients of the Efficiency Parameter Characteristics

\begin{tabular}{|c|c|c|c|c|c|c|}
\hline & $802.11 \mathrm{a}$ & $\begin{array}{l}802.11 \mathrm{n} \\
20 \mathrm{MHz}\end{array}$ & $\begin{array}{l}802.11 \mathrm{n} \\
40 \mathrm{MHz}\end{array}$ & $\begin{array}{c}802.11 \mathrm{ac} \\
20 \mathrm{MHz}\end{array}$ & $\begin{array}{c}802.11 \mathrm{ac} \\
40 \mathrm{MHz}\end{array}$ & $\begin{array}{c}802.11 \mathrm{ac} \\
80 \mathrm{MHz}\end{array}$ \\
\hline & \multicolumn{6}{|c|}{ Open space } \\
\hline$u$ & 0.04 & 0.9 & 1.1 & 0.04 & 0.5 & 0.4 \\
\hline \multirow[t]{2}{*}{$h$} & 2.2 & 7 & 6 & 4.7 & 2.5 & 9 \\
\hline & \multicolumn{6}{|c|}{ Single door } \\
\hline$u$ & 0.16 & 0.8 & 1.3 & 1.1 & 1.5 & 1.6 \\
\hline \multirow[t]{2}{*}{$h$} & 1.6 & 3.45 & 6.2 & 6 & 7 & 15 \\
\hline & \multicolumn{6}{|c|}{ Two doors } \\
\hline$u$ & 0.24 & 0.7 & 1.5 & 0.6 & 0.3 & 0.4 \\
\hline \multirow[t]{2}{*}{$h$} & 1.84 & 5.7 & 10 & 4.5 & 8.2 & 12 \\
\hline & \multicolumn{6}{|c|}{ Walls } \\
\hline$u$ & 0.7 & 1.3 & 2.6 & 1.8 & 2.1 & 2.76 \\
\hline$h$ & 2.1 & 5.5 & 6.8 & 5.2 & 7.6 & 9.2 \\
\hline
\end{tabular}

From the obtained results it follows that attenuation coefficients of characteristics can have an average value for all standards. Difference between standards will be determined with the help of the interval of deviations and initial coefficients $\mathrm{s}$ and $\mathrm{x}$. In order to obtain general estimation of the efficiency coefficient, the statement of the boundary of permissible variations is introduced for the attenuation coefficients. To this end, the following condition is written:

$$
\begin{aligned}
& u=\frac{1}{n} \sum_{i=1}^{n} u_{3} \pm \Delta u, \\
& h=\frac{1}{n} \sum_{i=1}^{n} h_{3} \pm \Delta h,
\end{aligned}
$$

where $\Delta u, \Delta h$ are the coefficients, which determine the boundaries of the permissible variations for the attenuation coefficients.

Having substituted the averaged values of regression and taking into account the permissible fluctuations, we will obtain:

$$
u=1.3 \pm 1.4(\mathrm{Mb} / \mathrm{m}), h=8 \pm 6.5(\mathrm{Mb} / \mathrm{m}) .
$$

Therefore, taking into account the architectural obstacles within the premises, it is possible to write the efficiency criterion for the wireless channels of the family of $802.11 x$ standards for the $5 \mathrm{GHz}$ frequency band in the following manner:

$$
K \approx \frac{s-(1,3 \pm 1,4) \cdot l-\Delta V}{V_{p l \text { max }}}
$$




$$
K_{p l} \approx \frac{x-(8 \pm 6,5) l}{V_{p l \text { max }}} .
$$

In order to check correctness of the obtained expressions, we will draw two charts of dependences between the efficiency coefficients for the wireless channels of the standard $802.11 \mathrm{n}$ in the $20 \mathrm{MHz}$ frequency band and permissible boundaries of change of the attenuation coefficients. Results are shown in Fig. 5.

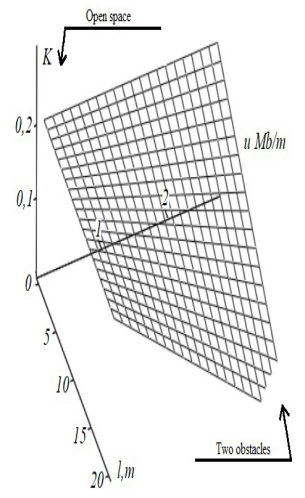

a

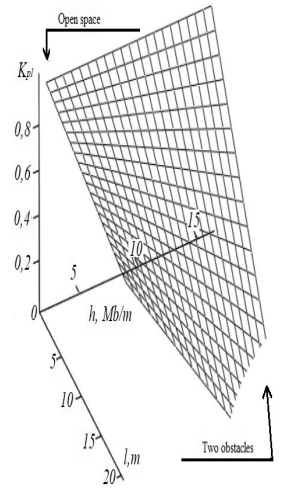

b

Fig. 5. Dependences: a - of the efficiency coefficient of the wireless channel upon $\Delta u$; $\mathrm{b}-$ of the coefficient of change of carrying capacity upon $\Delta h$.

\section{CONCLUSIONS}

The following specific features have been determined on the basis of the obtained results of the study of the wireless channels of the family of $802.11 \mathrm{x}$ standards in the $5 \mathrm{GHz}$ frequency band:

- $\quad$ presence of physical obstacles increases the level of the signal fluctuations before the obstacle and following the obstacle (the higher density of obstacles, the higher attenuation of signals; therefore, the level of fluctuations increases);

- $\quad$ parameter of carrying capacity at the physical level is in direct dependence on the density of obstacles;

- channel of the standard 802.11a, whose characteristic of the efficient rate of information transmission is almost linear one, is the most stable channel, while channel $802.11 \mathrm{ac}$ in the $80 \mathrm{MHz}$ frequency band is the most unstable channel. This fact allows stating that utilisation of channels having higher frequency bands causes an increase in the efficient rate of information transmission;

- on the basis of the obtained study results, it is possible to assume that the architectural obstacle that has low density has low coefficient of signal attenuation. 


\section{REFERENCES}

1. Rose, K., Eldridge, S., \& Chapin, L. (2015). The Internet of Things: An Overview. The Internet Society (ISOC), 1-50. Available at https://www.internetsociety.org/wp-content/ uploads/2017/08/ISOC-IoT-Overview-20151221-en.pdf

2. Perahia, E., \& Stacey, R. (2013). Next Generation Wireless LANs: 802.11n and 802.11ac. Cambridge: Cambridge University Press.

3. Mykhalevskiy, D. (2014). Evaluation of wireless information transmission channel settings of 802.11 wi-fi standard. Easten-European Journal of Enterprise Technologies, 6/9(72), 22-25. DOI: 10.15587/1729-4061.2014.31666.

4. Mykhalevskiy, D. (2017). Development of a spatial method for the estimation of signal strength at the input of the 802.11 standard receiver. Eastern-European Journal of Enterprise Technologies, 4/9(88), 29-36. DOI: 10.15587/1729-4061.2017.106925.

5. Mykhalevskiy, D., Vasylkivskiy, N., \& Horodetska, O. (2017). Development of a mathematical model for estimating signal strength at the input of the 802.11 standard receiver. Eastern-European Journal of Enterprise Technologies, 4/9(88), 38-43. DOI: 10.15587/1729-4061.2017.114191.

6. Mykhalevskiy, D.V., \& Huz, M.D. (2015). Estimation of the power distribution of the 802.11 standard transmitter in the room. International periodic scientific journal Sword, $1(38), 48-52$.

7. Deek, L., Garcia-Villegas, E., Belding, E., Lee, S. J., \& Almeroth, K. (2011). The impact of channel bonding on 802.11n network management. CoNEXT'11 Proceedings of the Seventh Conference on emerging Networking Experiments and Technologies 11, 1-12.

8. Foster, K. (2007). Radiofrequency exposure from wireless LANs utilizing Wi-Fi technology. Health Physics, 280-289. Available at https://pdfs.semanticscholar.org/ffa4/ af1900d204477c4640b390162456346faf10.pdf.

9. Mykhalevskiy, D.V., \& Horodetska, O.S. (2015). Estimation of speed of transmission of information for the family of standards $802.11 \mathrm{x}$ in the range $2.4 \mathrm{GHz}$. International periodic scientific journal Sword, 3(40), 43-47.

10. Chrysikos, T., \& Kotsopoulos, S. (2013). Site-specific validation of path loss models and large-scale fading characterization for a complex urban propagation topology at 2.4 GHz. Proceedings of the International MultiConference of Engineers and Computer Scientists, II, 1-6.

11. Mykhalevskiy, D.V. (2016). Investigation of sensitivity impact of receiver to effective data transmission rate. Proceedings of the 1st IEEE International Conference on Data Stream Mining \& Processing, Lviv, Ukraine, 369-372.

12. Aheeva, N.M., Lvovych, Y.Y., Shyian, P.L., \& Mykhalevskiy, D.V. (2016). Scientific Answers to Modern Questions: Technology in Technology (2 volumes). Odessa: Kupryenko S.V.

13. Hertoghs, Y., \& Maglione, R. (2014) Multi-service broadband network architecture. Broadband Forum Marketing Report, MR-316(1), 1-22. 


\title{
802.11 STANDARTA BEZVADU KANĀLU IZPĒTE \\ 5GHZ FREKVENČU JOSLĀ
}

\author{
D. V. Mihalevskijs
}

Kopsavilkums

Rakstā pētīti 802.11x ǵimenes standartu bezvadu pārraides kanāli $5 \mathrm{GHz}$ frekvenču joslā, ņemot vērā arhitektūras šksēršlu ietekmi telpās. Par galvenajiem parametriem pētījuma gaitā ir izvēlēti šādi parametri: efektīvs datu pārraides ātrums, signāla jauda uztvērēja ieejā, kā arī kanāla caurlaides spēja. Eksperimentālā pētījuma rezultātā atbilstoša matemātiskā izteiksme atklāta, lai novērtētu 802.11x ǵimenes standartu bezvadu kanālu efektivitātes kritēriju $5 \mathrm{GHz}$ frekvenču joslā, ņemot vērā attiecīgos arhitektūras šksēršlus telpās.

08.12.2018. 